Chronic Obstructive Pulmonary Diseases:

Journal of the COPD Foundation

\author{
Original Research
}

\title{
Patient-Reported Consequences of Community-Acquired Pneumonia in Patients with Chronic Obstructive Pulmonary Disease
}

Cara B. Pasquale, $\mathrm{MPH}^{1}$ Jeffrey Vietri, $\mathrm{PhD}^{2}$ Radmila Choate, $\mathrm{MPH}^{3}$ Angee McDaniel, PharmD ${ }^{4}$ Reiko Sato, $\mathrm{PhD}^{2}$ Kimbal D. Ford, PharmD ${ }^{5}$ Elisha Malanga, BS ${ }^{1}$ Barbara P. Yawn, MD, MSc ${ }^{1}$

\begin{abstract}
Community acquired pneumonia (CAP) carries high morbidity, mortality, and economic burden, which is even higher in adults diagnosed with chronic obstructive pulmonary disease (COPD). While several studies have assessed the clinical burden and mortality risk of CAP and COPD, very few studies focus on CAP burden from a COPD patient perspective. Individuals recently diagnosed with CAP and with pre-existing COPD were recruited through the COPD Foundation. The CAP Burden of Illness Questionnaire (CAP-BIQ), a content validated questionnaire assessing CAP symptomatology, duration of symptoms and CAP impact on work, activities and family, was administered at baseline and at 30-days follow-up.

Of the 490 participants recruited, 481 had data sufficient for analysis. The prevalence of respiratory-related symptoms was very high $(>90 \%)$ at the time of diagnosis with other generalized symptoms such as fatigue, trouble sleeping, headaches and confusion present in more than $60 \%$ of participants. Mean duration of symptoms varied from approximately 2 weeks for headaches and fever to more than a month for fatigue, wheezing, dyspnea, and cough. Employed participants missed an average of 21 days of work and those not employed missed 36 days of usual activities. Over $84 \%$ required help from family, friends or care givers.

CAP is a serious and burdensome condition for people with COPD, a condition that can impair activities for weeks, frequently requires care from family or friends, and includes lingering symptoms. The patient-reported impact of CAP reported in this study underscores the need for prevention strategies in this population.
\end{abstract}

Abbreviations: community-acquired pneumonia, CAP; chronic obstructive pulmonary disease, COPD; community-acquired pneumonia burden of illness questionnaire, CAP-BIQ; COPD Patient-Powered Research Network, COPD PPRN; Patient-Centered Outcomes Research Institute, PCORI; COPD Assessment Test, CAT; standard deviation, SD; Behavioral Risk Factor Surveillance System, BRFSS; Centers for Disease Control and Prevention, CDC

Funding Support: This study was sponsored by Pfizer.

Date of Acceptance: September 18, 2018

Citation: Pasquale CB, Vietri J, Choate R, et al. Patient-reported consequences of community-acquired pneumonia in patients with chronic obstructive pulmonary disease. Chronic Obstr Pulm Dis. 2019;6(2):132-144. doi: https://doi.org/10.15326/jcopdf.6.2.2018.0144

\begin{tabular}{l}
1 Research Department, COPD Foundation, Inc., Washington, D.C. \\
\hline 2 Patient \& Health Impact, Pfizer, Inc., Collegeville, Pennsylvania \\
\hline 3 College of Public Health, University of Kentucky Lexington, and \\
Consultant, COPD Foundation, Inc. \\
\hline Medical Affairs, Pfizer, Inc., Columbia, Missouri
\end{tabular}

5 Medical Affairs, Pfizer, Inc., Lexington, Kentucky

\section{Address correspondence to:}

Name: Cara B. Pasquale, MPH

Phone: 866-731-2673, ext. 312

Email: cpasquale@copdfoundation.org

\section{Keywords:}

COPD, community acquired pneumonia, patient reported outcomes, symptom burden, time to resolution 


\section{Introduction}

Community-acquired pneumonia (CAP) is a significant cause of morbidity and mortality affecting more than 5 million U.S. adults and resulting in $\$ 8$ billion in hospitalization costs annually. ${ }^{1-6}$ The $18-25$ million U.S. adults with chronic obstructive pulmonary disease ([COPD]-including chronic bronchitis and emphysema) ${ }^{7}$ have a higher risk of developing CAP with incidence rates 6 to 8 times that of healthy individuals in the same age group. ${ }^{2-4,8-10}$

CAP carries an increased risk of morbidity, mortality and economic burden for individuals with COPD compared to the general population. ${ }^{11-14}$ In addition, CAP greatly increases the likelihood of a COPD exacerbation ${ }^{15}$ which results in major disruptions to patients' and families' lives with 587,000 hospitalizations and 1.86 million emergency department visits each year. ${ }^{6}$ An exacerbation may begin a downward spiral from which the individual may only slowly or never fully recover. ${ }^{16-18}$

To date, much of the CAP literature focuses on the burden and recovery from CAP in the general population, with only a few publications addressing the patient-reported burden and impact of CAP. ${ }^{5,19-22}$ Even less data is available on the impact on individuals with COPD.

In addition to respiratory symptoms, CAP is associated with generalized symptoms such as fatigue, weakness, balance problems, confusion or trouble thinking and sleep disturbances. ${ }^{19,20,22}$ Many of these symptoms are more common and may take longer to resolve in older adults and those with chronic disease comorbidities such as COPD. ${ }^{13,23-25}$ Such data are rarely available from health records, therefore, a full understanding of the burden of CAP requires use of direct patient reporting among those recently diagnosed with CAP. Patient-reported outcome data may provide the insights needed to develop policies, guidelines and prevention strategies for COPD patients who are at increased risk of developing CAP. The objectives of this study were to: (1) assess the symptom burden of CAP; (2) report time to symptom recovery; and (3) assess the impact of CAP on daily activities from the COPD patient perspective.

\section{Methods}

\section{Study Design}

This survey study included 2 surveys. A baseline survey was completed within 120 days of the onset of self-reported CAP which was defined as being told by a health care provider (e.g., doctor, nurse, etc.) they had pneumonia. The follow-up survey was requested 30 days later. Both surveys queried about CAP-related symptoms and impact of CAP on work and daily life. Participants were a convenience sample of adults 18 years of age and older who reported they had been diagnosed with COPD, emphysema or chronic bronchitis. The study was approved by a central institutional review board, and all participants provided informed consent prior to their participation. Multiple resources of the COPD Foundation were used to recruit potential participants (See Supplemental Table 1 in the online supplement). These included Facebook postings, posts on the COPD Foundation's COPD360Social online network, and outreach to existing research participants in the COPD PatientPowered Research Network (COPD PPRN), a secure online interactive patient registry maintained by the COPD Foundation and funded by the Patient-Centered Outcomes Research Institute (PCORI). Individuals interested in participating were directed to the study portal within the COPD PPRN platform and invited to complete a screening questionnaire to self-report diagnosed COPD and recent episodes of pneumonia. (See Supplemental Table 2 in the online supplement). If eligible (reported having COPD [chronic obstructive pulmonary disease, emphysema or chronic bronchitis] and being diagnosed with pneumonia within the previous 120 days), they were asked to provide eConsent. Consented participants were then directed to a baseline survey to complete at enrollment, with the follow-up survey available 30 days after completion of the baseline data. Study participants were reimbursed $\$ 10$ after completing each of the 2 surveys.

\section{Measures}

The baseline survey collected basic demographic information including age, gender, highest education attained, income, employment, insurance status, and living arrangements. Self-reported presence of other chronic diseases including diabetes, hypertension, asthma and heart disease was also queried. All were asked to complete the COPD Assessment Test (CAT) 
which provides information on the respiratory and general symptom burden associated with COPD. ${ }^{26}$ Information on the burden of CAP was collected using a modified version of the CAP-Burden of Illness Questionnaire (CAP-BIQ), which is a contentvalidated patient-reported outcome measure. ${ }^{19,20}$ The CAP-BIQ consists of questions developed through a qualitative process including concept elicitation interviews and cognitive debriefing, and includes items on symptoms, comorbid conditions, as well as other impacts of CAP on daily life and activities. Participants were also asked if they had received a chest radiograph or computerized tomography to diagnose or confirm their CAP. The follow-up survey focused on CAP symptoms that were reported to be unresolved at the time of the baseline survey completion. A COPD patient stakeholder reviewed all recruitment and study materials to ensure their readability, clarity, and to assess participant burden and relevance to the COPD community.

\section{Data Collection \& Follow-up}

All information was collected online through the secure COPD PPRN dashboard assigned to the participant at the time of providing eConsent. If a consented participant did not complete the baseline survey immediately, they received email reminders on days 1, 2, and 7 after providing consent. On or shortly after day 8 , participants who had not responded but provided a phone number were called by a representative of the C.O.P.D. Information Line, a service of the COPD Foundation which provides peerto-peer information and referral for COPD patients and caregivers. No surveys were administered by telephone. If the participant had not completed the survey on the 30th day after providing consent, a final reminder email to complete the baseline survey was sent. Participants were notified of the availability of the follow-up survey 30 days after the completion of the baseline, and when necessary were reminded via email on days 31 and 37. For those who had still not responded, they were telephoned on the 8th day the follow-up survey was available, and a final email reminder was sent 60 days after completion of the baseline survey. Participant's eligibility to complete the baseline survey was terminated at 120 days from the reported date of CAP diagnosis. (See Figure 1.)

\section{Figure 1. Community-Acquired Participant Disposition}

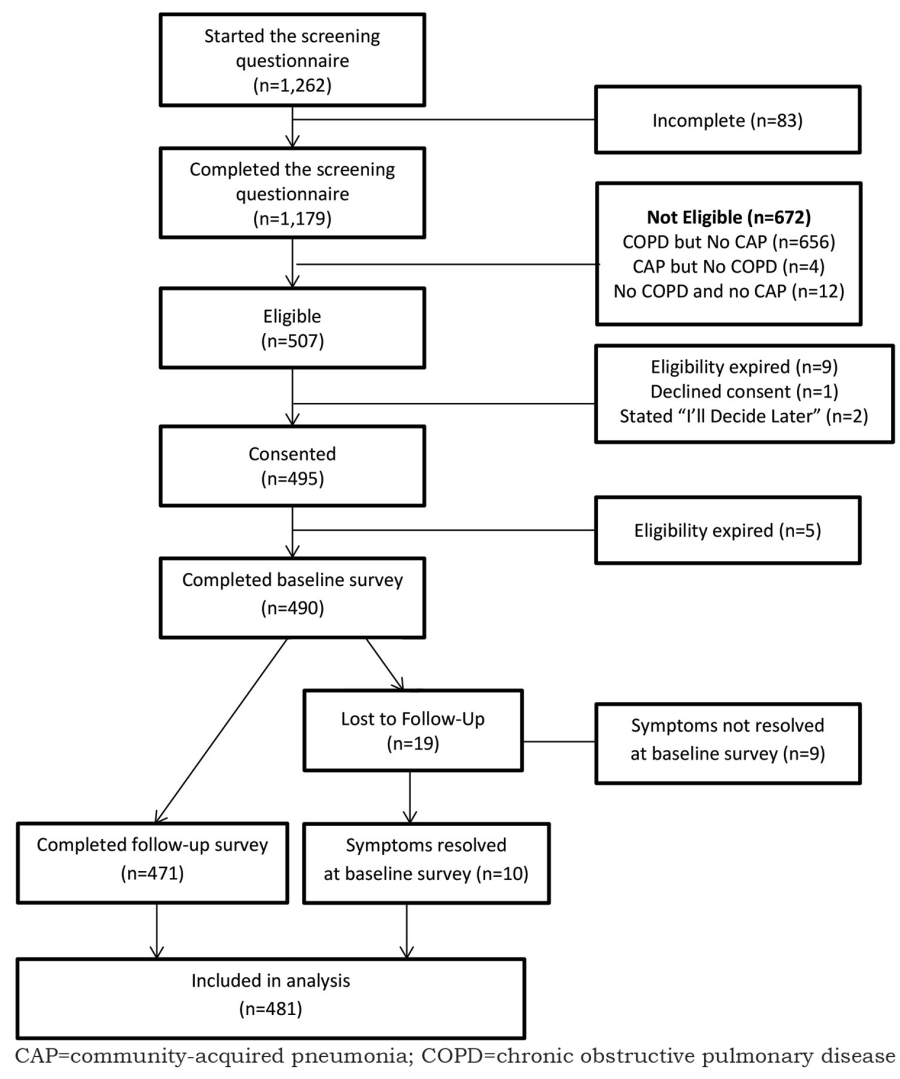

\section{Statistical Analysis}

Analyses were completed using data from all participants who either submitted both the baseline and the follow-up surveys or reported that their CAP symptoms had resolved at the time of the baseline survey.

Descriptive statistics were computed for the participants' baseline characteristics, including demographics, baseline CAT score and prevalence of CAP symptoms at diagnosis. Mean and standard deviation (SD) as well as median and interquartile range (Q1-Q3) were calculated for continuous variables, and categorical variables were summarized by frequencies and proportions. For those who reported at least 1 day with any CAP symptom on the CAP-BIQ, time to symptom resolution was calculated and reported as mean (SD), median and (Q1-Q3). Time to return to work, to usual level of work productivity or for those not working, usual daily activities, as well as the number of days of missed work or missed daily activities, were calculated based on the time of the survey completion and the date of pneumonia diagnosis provided by the participant. The frequency of patient-reported 
impact of CAP symptoms on family and daily life such as trouble with self-care, inability to get out of the home or drive and need for caregiver assistance, were also computed. As exploratory analyses, results were analyzed stratified by hospitalization for CAP (yes/no) and age group ( $<50,50$ to 64 or $\geq 65$ years of age). Values between the strata were compared using t-test or analysis of variance for continuous variables, and Chi-squared test for categorical variables. The significance level was set at 0.05. All statistical analyses were performed using SAS 9.4.

\section{Results}

A total of 1262 individuals initiated the screening questionnaire. Of these, 1179 (93.4\%) completed the questionnaire and 507 were eligible for enrollment. (Figure 1). There were 481 participants with sufficient data to be included in the analysis either due to the complete resolution of symptoms at the baseline survey $(\mathrm{n}=10)$ or by completion of both the baseline and follow-up surveys $(n=471)$. Although CAP diagnoses were self-reported without medical record verification, $96.5 \%$ of participants stated they did have a chest radiograph or computerized tomography to diagnose or confirm their CAP.

The participants' mean age was 48.9 years (SD 11.1 years), and 64\% were men. Most were white and approximately half had completed a college or postgraduate education, $52 \%$ were currently employed and 49\% were current smokers. Additional baseline characteristics of respondents including the CAT results (mean 24.9 which is high and the mean was not significantly different across age groups) are depicted in Table 1. Self-reported chronic conditions included asthma (23.5\%), hypertension (23.5\%), diabetes (15.4\%), and heart disease (8.5\%). Of the 481 participants included in the data analysis, 91.1\% ( $\mathrm{n}=438)$ reported being hospitalized for their CAP. The mean time between the diagnosis of CAP and completion of the baseline survey was 70.4 days (SD 26.7 days, median 73 days). Average time to completion of the follow-up survey was 32.8 days (SD 26.6 days, median 35 days) after completion of the baseline survey.

Over $90 \%$ of all participants reported the presence of respiratory-related symptoms including dyspnea, cough, thick mucus or phlegm, wheezing, pain from cough, as well as fever, and sweats at the time of CAP diagnosis. Generalized symptoms of weak appetite and trouble sleeping were reported by more than $60 \%$ while headaches, confusion or trouble thinking were reported by about half of the participants as being present at the time of CAP diagnosis. (Table 2).

On average, most respiratory-related symptoms required 3 weeks or longer for resolution. Some of the more generalized symptoms such as headaches, gastrointestinal symptoms, chills and fever required less time to return to normal. Figure 2 displays the mean time to symptom resolution.

\section{CAP Impact on Daily Activities}

CAP had significant impact on both work and usual activities. (Table 3). Of those employed part or full time, $96.9 \%$ reported missing work with an average of 21.6 days of missed work and another 14 days required to return to "usual" job performance. For those not working, $87.5 \%$ reported missing 1 or more days of usual activities with an average of 36.1 days missed, and an additional 10 days on average to return to their usual activity performance. Overall, $84.6 \%$ of the sample reported that they required help from family, friends or caregivers during their CAP recovery, with an average of 28.2 days of help needed. (Table 4).

CAP-related cough and weakness were reported to have broad impacts on the participants' lives that are seldom recorded in medical encounters. Figure 3 highlights that the majority of patients reported a negative impact of symptoms on others in their household as well their ability to go outside their home or visit or talk with others. Participants also used the opportunity to provide comments in an open text field to report problems with incontinence due to cough $(n=6)$. One participant summarized the impact of CAP by saying "My 'normal' has been adjusted downward, again" and another likened their experience with CAP added onto their COPD as "in an invisible prison".

\section{Exploratory Impact of Hospitalization and Age}

Most participants reported being hospitalized due to CAP. Among those hospitalized, almost all reported symptoms were more frequent compared to those treated as outpatients with the exception of dyspnea and weak appetite which were equally common in both groups. (Table 2). Time required for resolution of symptoms was similar in hospitalized and nonhospitalized participants, except for cough, phlegm, fever and trouble sleeping, which on average lasted 


\section{Table 1. Baseline Demographic Characteristics of Respondents}

\begin{tabular}{|c|c|c|c|c|c|c|}
\hline & $\begin{array}{l}\text { Overall } \\
N=481\end{array}$ & $\begin{array}{l}\text { Hospitalized } \\
\begin{array}{c}\mathrm{N}=438 \\
(91.1 \%)\end{array}\end{array}$ & $\begin{array}{c}\text { Non- } \\
\text { hospitalized } \\
N=43 \\
(8.9 \%)\end{array}$ & $\begin{array}{c}\text { Age }<50 \\
N=274 \\
(57.0 \%)\end{array}$ & $\begin{array}{c}\text { Age } 50-64 \\
N=160 \\
(33.3 \%)\end{array}$ & $\begin{array}{c}\text { Age } \geq 65 \\
N=47 \\
(9.7 \%)\end{array}$ \\
\hline \multicolumn{7}{|l|}{ Age, years } \\
\hline Mean $(\mathrm{SD})^{\mathrm{c}, \mathrm{f}}$ & $48.9(11.1)$ & $47.8(10.5)$ & $60.2(11.4)$ & $41.4(5.4)$ & $55.1(3.8)$ & $72.3(5.9)$ \\
\hline Median $(\mathrm{Q} 1$ - Q3) & $47(41-55)$ & $47(40-53)$ & $59(54-69)$ & $42[38-46]$ & $54(52-58]$ & $70.5[68-77.5]$ \\
\hline \multicolumn{7}{|l|}{ Gender, $\mathrm{n}(\%)^{\mathrm{a}}$} \\
\hline Male & $307(64.0)$ & $286(65.5)$ & $21(48.8)$ & $179(65.6)$ & 95 (59.4) & $33(70.2)$ \\
\hline Female & $173(36.0)$ & $151(34.6)$ & $22(51.2)$ & $94(34.4)$ & $65(40.6)$ & $14(29.8)$ \\
\hline \multicolumn{7}{|l|}{ Ethnicity, n (\%) } \\
\hline Hispanic or Latino & $65(13.5)$ & $62(14.2)$ & $3(7.1)$ & $42(15.4)$ & $23(14.4)$ & -- \\
\hline \multicolumn{7}{|l|}{ Racial Background, n (\%) ${ }^{\mathrm{e}}$} \\
\hline White & $387(79.8)$ & $351(80.5)$ & $36(83.7)$ & $233(85.4)$ & $112(70.0)$ & $42(91.3)$ \\
\hline Black or African American & $72(15.1)$ & $69(15.8)$ & $3(7.0)$ & 29 (10.6) & $40(25.0)$ & $3(6.5)$ \\
\hline Other (including multiple races) & $20(4.2)$ & $16(3.7)$ & $4(9.3)$ & $11(4.0)$ & $8(5.0)$ & $1(2.2)$ \\
\hline \multicolumn{7}{|l|}{ Living/Domestic Situation, $\mathrm{n}(\%)^{\mathrm{a}, \mathrm{f}}$} \\
\hline Living alone & $68(14.1)$ & 59 (13.5) & $9(20.9)$ & $27(9.9)$ & $26(16.3)$ & $15(31.9)$ \\
\hline $\begin{array}{l}\text { Living with a partner/spouse/ family/ } \\
\text { friends/other }\end{array}$ & $413(85.9)$ & $379(86.5)$ & $34(79.1)$ & $247(90.1)$ & $134(83.8)$ & $32(68.1)$ \\
\hline \multicolumn{7}{|l|}{ Employment Status, n (\%) $)^{\mathrm{c}, \mathrm{f}}$} \\
\hline Employed, full-time & $164(34.1)$ & $159(36.3)$ & $5(11.6)$ & $126(46.0)$ & $38(23.8)$ & -- \\
\hline Employed, part-time & $88(18.34)$ & $84(19.2)$ & $4(9.3)$ & $58(21.2)$ & $28(17.5)$ & $2(4.3)$ \\
\hline Homemaker & $21(4.4)$ & $19(4.3)$ & $2(4.7)$ & $14(5.1)$ & $7(4.4)$ & -- \\
\hline Unemployed & $65(13.5)$ & $64(14.6)$ & $1(2.3)$ & $46(16.8)$ & $19(11.9)$ & -- \\
\hline Retired & 89 (18.5) & 74 (16.9) & 15 (34.9) & $22(8.0)$ & 29 (18.1) & $38(80.9)$ \\
\hline Disabled & $45(9.4)$ & $32(7.3)$ & $13(30.2)$ & $6(2.2)$ & 33 (20.6) & $6(12.8)$ \\
\hline Other & $9(1.9)$ & $6(1.4)$ & $3(7.0)$ & $2(0.8)$ & $6(3.8)$ & $1(2.1)$ \\
\hline \multicolumn{7}{|l|}{ Education Level, $\mathrm{n}(\%)^{\mathrm{e}}$} \\
\hline Secondary/high school & 78 (16.2) & $72(16.4)$ & $6(14.0)$ & $39(14.2)$ & $30(18.7)$ & $9(19.2)$ \\
\hline Some college & $171(35.6)$ & $155(35.4)$ & $16(37.2)$ & 89 (32.5) & $62(38.8)$ & $20(42.6)$ \\
\hline College degree & $182(37.8)$ & $168(38.4)$ & $14(32.6)$ & $127(46.4)$ & $46(28.7)$ & $9(19.2)$ \\
\hline Postgraduate degree & $50(10.4)$ & $43(9.8)$ & $7(16.3)$ & $19(6.9)$ & $22(13.8)$ & $9(19.2)$ \\
\hline \multicolumn{7}{|l|}{ Current Health Insurance, $n(\%)^{a, f}$} \\
\hline Private & $238(49.5)$ & $221(50.5)$ & $17(39.5)$ & $162(59.1)$ & $68(42.5)$ & $8(17.0)$ \\
\hline Medicare & $156(32.4)$ & $144(32.9)$ & $12(27.9)$ & $77(28.1)$ & 49 (30.6) & $30(63.8)$ \\
\hline Medicare/Medicaid dual eligible & $27(5.6)$ & $20(4.6)$ & $7(16.3)$ & $6(2.2)$ & $15(9.4)$ & $6(12.8)$ \\
\hline Medicaid & $29(6.0)$ & $26(5.9)$ & $3(7.0)$ & $11(4.0)$ & $18(11.3)$ & - \\
\hline Decline/Missing/Other & $16(3.3)$ & $13(3.0)$ & $3(7.0)$ & $4(1.5)$ & $9(5.6)$ & $3(6.4)$ \\
\hline None & $15(3.1)$ & $14(3.2)$ & $1(2.3)$ & $14(5.1)$ & $1(0.6)$ & - \\
\hline \multicolumn{7}{|l|}{ Household Income, $\mathrm{n}(\%)^{\mathrm{c}, \mathrm{f}}$} \\
\hline Less than $\$ 20,000$ & $23(4.8)$ & $16(3.7)$ & $7(16.3)$ & $3(1.1)$ & $14(8.8)$ & $6(12.8)$ \\
\hline$\$ 20,001$ to $\$ 40,000$ & $80(16.6)$ & $64(14.6)$ & $16(37.2)$ & $37(13.5)$ & $28(17.5)$ & $15(31.9)$ \\
\hline$\$ 40,001$ to $\$ 60,000$ & $117(24.3)$ & $110(25.1)$ & $7(16.3)$ & $67(24.5)$ & $42(26.3)$ & $8(17.0)$ \\
\hline$\$ 60,001$ to $\$ 80,000$ & $172(35.8)$ & $170(38.8)$ & $2(4.7)$ & $125(45.6)$ & $43(26.9)$ & $4(8.5)$ \\
\hline$\$ 80,001$ and above & $72(15.0)$ & $66(15.1)$ & $6(14.0)$ & 40 (14.6) & $28(17.5)$ & $4(8.5)$ \\
\hline
\end{tabular}


Smoking History, n (\%) ${ }^{c, f}$

\begin{tabular}{|c|c|c|c|c|c|c|}
\hline Current smoker & 235 (48.9) & $228(52.1)$ & 7 (16.3) & 169 (61.7) & $65(40.6)$ & $1(2.1)$ \\
\hline Former smoker & $118(24.5)$ & 87 (19.9) & $31(72.1)$ & $23(8.4)$ & $54(33.8)$ & $41(87.2)$ \\
\hline Never smoker & 128 (26.6) & $123(28.1)$ & 5 (11.6) & $82(29.9)$ & $41(25.6)$ & $5(10.6)$ \\
\hline Mean (SD) & $24.1(8.4)$ & $24.0(8.5)$ & $24.3(8.1)$ & $24.9(7.8)$ & $23.1(9.5)$ & $22.3(7.5)$ \\
\hline Median (Q1- Q3) & $23(18-31)$ & $23(18-31)$ & $26(16-30)$ & $24(21-32)$ & $22(16-32)$ & $21(16-27)$ \\
\hline \multicolumn{7}{|l|}{ CAT Score Categories ${ }^{f}$} \\
\hline Low impact (6-9) & $11(2.3)$ & $11(2.5)$ & -- & $6(2.2)$ & $5(3.1)$ & -- \\
\hline Medium impact (10-20) & $147(30.6)$ & $132(30.3)$ & $15(34.9)$ & $60(22.1)$ & 65 (40.6) & $22(46.8)$ \\
\hline High impact (21-30) & $190(39.5)$ & 172 (39.5) & 18 (41.9) & $132(48.7)$ & 41 (25.6) & $17(36.2)$ \\
\hline Very high impact (>30) & $125(26.0)$ & $115(26.4)$ & $10(23.3)$ & 72 (26.6) & $46(28.8)$ & $7(14.9)$ \\
\hline $\begin{array}{l}\text { For stratification by hospital } \\
{ }^{\mathrm{a}} p<0.05 \\
\mathrm{~b}_{p}<0.01 \\
{ }^{\mathrm{c}} p<0.001 \\
\text { For stratification by age grou } \\
\mathrm{d}_{p}<0.05 \\
\mathrm{e}_{p}<0.01 \\
{ }^{\mathrm{f}} p<0.001 \\
\text { SD }=\text { standard deviation; } \mathrm{Q} 1-\end{array}$ & & & & & & \\
\hline
\end{tabular}

\section{Table 2. Prevalence of Community-Acquired Pneumonia Symptoms at Diagnosis}

\begin{tabular}{|c|c|c|c|c|c|c|}
\hline & $\begin{array}{l}\text { Overall } \\
N=481\end{array}$ & $\begin{array}{c}\text { Hospitalized } \\
\begin{array}{c}\mathrm{N}=438 \\
(91.1 \%)\end{array}\end{array}$ & $\begin{array}{c}\text { Non- } \\
\text { hospitalized } \\
N=43 \\
(8.9 \%)\end{array}$ & $\begin{array}{c}\text { Age }<50 \\
N=274 \\
(57.0 \%)\end{array}$ & $\begin{array}{c}\text { Age } 50-64 \\
N=160 \\
(33.3 \%)\end{array}$ & $\begin{array}{c}\text { Age } \geq 65 \\
N=47 \\
(9.7 \%)\end{array}$ \\
\hline & $\mathrm{n}(\%)$ & $\mathrm{n}(\%)$ & $\mathrm{n}(\%)$ & $\mathrm{n}(\%)$ & $\mathrm{n}(\%)$ & $\mathrm{n}(\%)$ \\
\hline Fever ${ }^{c, f}$ & $426(88.8)$ & $403(92.2)$ & $23(53.5)$ & $263(96.3)$ & $138(86.3)$ & $25(53.2)$ \\
\hline Cough $^{d}$ & $476(99.0)$ & $434(99.1)$ & $42(97.7)$ & $274(100.0)$ & $157(98.1)$ & $45(95.7)$ \\
\hline Chills $^{\mathbf{c}, \mathbf{f}}$ & $372(77.5)$ & $353(80.8)$ & $19(44.2)$ & $240(87.9)$ & $114(71.3)$ & $18(38.3)$ \\
\hline Sweats ${ }^{c, f}$ & $400(83.3)$ & $379(86.7)$ & $21(48.8)$ & $255(93.4)$ & $129(80.6)$ & $16(34.0)$ \\
\hline Pain from Coughing ${ }^{c, f}$ & $433(90.0)$ & $405(92.5)$ & $28(65.1)$ & $266(97.1)$ & $139(86.9)$ & $28(59.6)$ \\
\hline Thick Mucus or Phlegm with Cough ${ }^{\mathrm{b}, \mathrm{f}}$ & $446(92.7)$ & $411(93.8)$ & $35(81.4)$ & $269(98.2)$ & $141(88.1)$ & $36(76.6)$ \\
\hline Headachesc,f & $349(72.7)$ & $328(75.1)$ & $21(48.8)$ & $241(88.3)$ & $97(60.6)$ & $11(23.4)$ \\
\hline Tiredness & $480(99.8)$ & $437(99.8)$ & $43(100.0)$ & $274(100.0)$ & $160(100.0)$ & $46(97.9)$ \\
\hline Body Aches d & $476(99.0)$ & 435 (99.3) & $41(95.4)$ & $274(100.0)$ & $158(98.8)$ & $44(93.6)$ \\
\hline Dyspnead $^{d}$ & $461(95.8)$ & $418(95.4)$ & $43(100.0)$ & $269(98.2)$ & $149(93.1)$ & $43(91.5)$ \\
\hline Confusion/Trouble Thinking ${ }^{c, f}$ & $288(60.0)$ & $275(62.9)$ & $13(30.2)$ & $190(69.3)$ & $83(51.9)$ & $15(32.6)$ \\
\hline Weak Appetite $^{\mathrm{f}}$ & $427(88.8)$ & $390(89.0)$ & $37(86.1)$ & 262 (95.6) & $131(81.9)$ & $34(72.3)$ \\
\hline Diarrhea, Vomiting, or Nausea ${ }^{b, f}$ & $274(57.0)$ & 261 (59.6) & $13(30.2)$ & $171(62.4)$ & $90(56.3)$ & $13(27.7)$ \\
\hline Wheezing ${ }^{a, f}$ & $438(91.1)$ & $403(92.0)$ & $35(81.4)$ & $268(97.8)$ & $139(86.9)$ & $31(66.0)$ \\
\hline Trouble Sleeping ${ }^{c, f}$ & $427(88.8)$ & $398(90.9)$ & $29(67.4)$ & $265(96.7)$ & $133(83.1)$ & $29(61.7)$ \\
\hline $\begin{array}{l}\text { For stratification by hospitalization status: } \\
\text { a } p<0.05 \\
\text { b } p<0.01 \\
{ }^{c} p<0.001 \\
\text { For stratification by age group: } \\
\text { d } p<0.05 \\
e_{p<0.01} \\
{ }^{p} p<0.001\end{array}$ & & & & & & \\
\hline
\end{tabular}




\section{Figure 2. Time to Symptom Resolution}

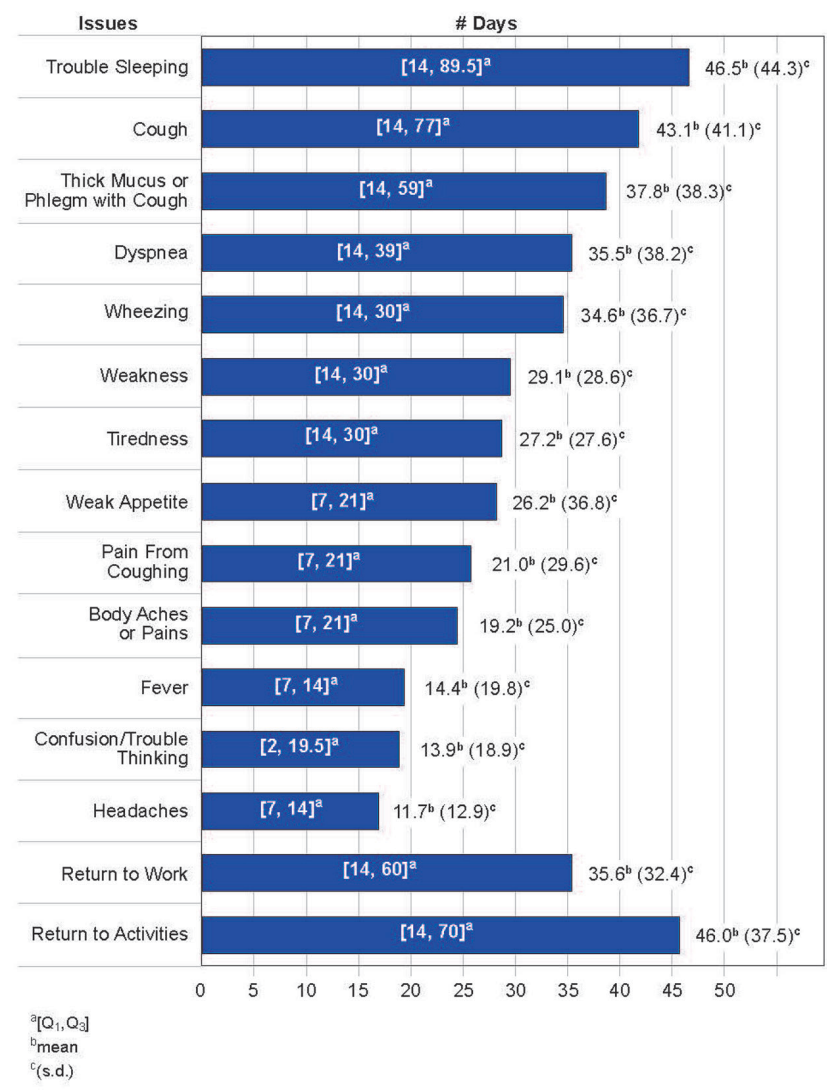

longer in those hospitalized. Those hospitalized due to CAP experienced more missed days of work and activities as well as a longer period to return to usual job performance and usual activities. (Table 3).

The prevalence of all reported symptoms differed according to age group, with lower prevalence in the older age groups, though it is important to note that less than $10 \%$ of the participants were 65 years of age or older. Age did not appear to lengthen the time to recovery for most symptoms with the exception of coughing, pain from coughing, thick phlegm and fever in which longer resolution time was associated with older age. (See Supplemental Table 3 in the online supplement.)

\section{Discussion}

In this group of individuals with COPD and CAP, numerous respiratory symptoms were reported that required an average of 3 or more weeks to resolve. In addition to respiratory symptoms, participants experienced fatigue, weakness, poor appetite, confusion or trouble thinking, body aches, and pain associated with their coughs. The burden of CAP resulted in missed work and usual activities for almost all individuals with an average of 21 missed days of work for the employed and 36.5 days of missed activities for those who were not employed. Returning to usual job performance or usual level of activities required an even longer period of time. The impact of the CAP was also felt by the individuals' families and care givers with almost $85 \%$ of participants reporting they required help with daily chores and self-care. Almost half reported they woke others in their home with their coughing or had sweats or chills that woke their sleeping partner. While pneumonia is always a potentially serious diagnosis, the burden was extensive among this group of people with COPD.

In a similarly designed survey study of U.S. adults with CAP by Wyrwich et al, the same CAP-BIQ instrument was used to identify symptom frequency, duration and impact from the patients' perspective. ${ }^{19}$ That study included 500 individuals in the baseline survey whom, as in the present study, had self-reported CAP within the past 120 days. However, there are noteworthy differences between the 2 studies: first, $100 \%$ of our patient population has self-reported COPD versus COPD self-reported in $24.4 \%$ of Wyrwich et al's community-based population and secondly, the mean age of our population was 48.9 years versus 62.4 years for the Wyrwich et al group. The comparison of selected common symptom frequency and time to resolution in the 2 populations are shown in Table 4 .

The higher prevalence of most of the common symptoms, the longer time to symptom recovery, greater numbers of missed work and activity days, as well as the greater percentage of individuals requiring assistance and for a longer period of time, highlights the even greater burden CAP places on people with COPD compared to a general community population reported in the Wyrwich et al studies. ${ }^{19,20}$ While Wyrwich et al did not report the specific data for their $24.4 \%$ subsample with COPD, they did report that the individuals with COPD/emphysema had the longest time to recovery compared to those without COPD and that the younger COPD/emphysema patients had the longest recovery period. ${ }^{20}$ Insufficient data was available to do statistical comparisons.

Other studies of CAP impact included a study of patients in a Canadian trial of a treatment pathway for CAP. ${ }^{22,23}$ In the Canadian study patients were on average older (mean of 61.6 years) and only $26 \%$ 


\section{Table 3. Impact of Community-Acquired Pneumonia and COPD on Work and Activities}

\begin{tabular}{|c|c|c|c|c|c|c|c|}
\hline & $\mathrm{N}$ & Overall & Hospitalized & $\begin{array}{l}\text { Non- } \\
\text { hospitalized }\end{array}$ & Age $<50$ & Age 50-64 & Age $\geq 65$ \\
\hline Currently Employed, n $(\%)^{c, f}$ & 481 & & & & & & \\
\hline Yes & & $256(53.2)$ & $246(56.2)$ & $10(23.3)$ & $183(66.8)$ & $70(43.8)$ & $3(6.4)$ \\
\hline No & & $225(46.8)$ & $192(43.8)$ & $33(76.7)$ & $91(33.2)$ & $90(56.3)$ & 44 (93.6) \\
\hline $\begin{array}{l}\text { Missed work due to } \mathrm{CAP}^{\mathrm{g}} \mathrm{n}(\%) \\
\text { Still unable to return to work due to } \\
\text { recent CAPg }\end{array}$ & 256 & 248 (96.9) & $239(97.2)$ & $9(90.0)$ & $176(96.2)$ & $69(98.6)$ & $3(100.0)$ \\
\hline At first survey, n (\%) & 248 & 79 (31.9) & 78 (32.6) & $1(11.1)$ & 59 (33.5) & $20(29.0)$ & - \\
\hline At second survey, n (\%) & 78 & $8(10.3)$ & $7(9.1)$ & $1(100.0)$ & $7(12.1)$ & $1(5.0)$ & -- \\
\hline $\begin{array}{l}\text { Number of days of work missed due } \\
\text { to } \text { CAP }^{\mathrm{i}, \mathrm{a}} \text { (total) } \text { (t,d }^{\mathrm{b}}\end{array}$ & 246 & & & & & & \\
\hline Mean (SD) & & $21.6(21.4)$ & $21.8(20.8)$ & $15.8(33.3)$ & $20.5(22.6)$ & $25.0(17.7)$ & $2.3[1.5]$ \\
\hline Median [Q1- Q3] & & $14.5[8-28]$ & $15[9-29]$ & $6[2-7]$ & $14[9-21]$ & 26 [8-36] & $2(1-4)$ \\
\hline $\begin{array}{l}\text { Number of days to return to usual job } \\
\text { performance after recent } \text { CAP }^{\mathbf{j}} \text { (total) }^{\mathrm{f}}\end{array}$ & 175 & & & & & & \\
\hline Mean (SD) & & $35.6(32.4)$ & $36.6(32.8)$ & $15.3(10.0)$ & $44.1(34.8)$ & $15.7(10.5)$ & $16.0(10.1)$ \\
\hline Median [Q1 - Q3] & & 21 [14-60] & 21 [14-63] & 14 [7-24] & 30 [14-78] & 14 [7-21] & 14 [7-27] \\
\hline $\begin{array}{l}\text { Missed any days of usual daily } \\
\text { activities due to } \mathbf{C A P}^{\mathrm{h}} \mathrm{n}(\%)\end{array}$ & 224 & $196(87.5)$ & $169(88.5)$ & $27(81.1)$ & $82(90.1)$ & 74 (83.2) & 40 (90.9) \\
\hline
\end{tabular}

Still unable to return to usual daily

activities due to recent $\mathbf{C A P}^{\mathrm{h}}$

\begin{tabular}{|c|c|c|c|c|c|c|c|}
\hline At first survey, n (\%) ${ }^{\mathrm{d}}$ & 196 & 79 (40.3) & $70(41.4)$ & $9(33.3)$ & $26(31.7)$ & $39(52.7)$ & $14(35.0)$ \\
\hline At second survey, n (\%) & 78 & 35 (44.9) & $30(43.5)$ & $5(55.6)$ & 9 (34.6) & 17 (43.6) & $9(69.2)$ \\
\hline $\begin{array}{l}\text { Number of days of usual daily } \\
\text { activities missed due to } \text { CAP }^{\mathbf{i}} \text { (total) }^{\mathrm{b}}\end{array}$ & 195 & & & & & & \\
\hline Mean (SD) & & $36.1(36.1)$ & 37.7 (35.9) & $26.1(36.4)$ & $32.0(29.6)$ & $42.3(39.8)$ & $33.1(40.0)$ \\
\hline Median [Q1 - Q3] & & $22[10-43] 2$ & 22 [14.5-45] & $10[5-30]$ & 22 [16-32] & 30 [10-60] & $14[5-47]$ \\
\hline $\begin{array}{l}\text { Number of days to return to usual daily } \\
\text { activities after recent } \mathbf{C A P}^{\mathbf{j}} \text { (total) } \text { (te }^{\mathrm{c}}\end{array}$ & 136 & & & & & & \\
\hline Mean (SD) & & $46.0(37.5)$ & $50.6(38.2)$ & $19.2(16.5)$ & $59.5(40.3)$ & $33.4(26.8)$ & $34.9(35.9)$ \\
\hline Median [Q1 - Q3] & & $30[14-70] 3$ & 30 [21-80.5] & 14 [7-25.5] & 60 [25.5-91] & 30 [14-53.5] & $17.5[7-60]$ \\
\hline $\begin{array}{l}\text { Patients with family/ friends caregiver } \\
\text { help during CAP, } n(\%)\end{array}$ & 481 & 407 (84.6) & 375 (85.6) & $32(74.4)$ & 240 (87.6) & $127(79.4)$ & $40(85.1)$ \\
\hline $\begin{array}{l}\text { Number of days of family/ friends care- } \\
\text { giver help needed during CAP }{ }^{\mathbf{k}} \text { (total) }^{\mathrm{b}}\end{array}$ & 405 & & & & & & \\
\hline Mean (SD) & & $28.2(27.5)$ & 28.4 (26.5) & $25.4(38.1)$ & $28.2(25.0)$ & $26.7(26.1)$ & $33.0(42.7)$ \\
\hline Median [Q1 - Q3] & & 21 [14-30] & 21 [14-30] & 14 [2-21] & 21 [14-30] & 21 [14-30] & $7[4.5-52]$ \\
\hline
\end{tabular}

For stratification by hospitalization status:

${ }^{\mathrm{a}} p<0.05,{ }^{\mathrm{b}} p<0.01,{ }^{\mathrm{c}} p<0.001$

For stratification by age group:

$\mathrm{d}_{p<0.05},{ }^{\mathrm{e}} p<0.01,{ }_{p}^{\mathrm{f}}<0.001$

gamong currently employed patients; hamong currently not employed patients; ${ }^{\text {ifor }}$ those still unable to return to work/usual daily activities- time from CAP diagnosis till last survey, ${ }^{j}$ among those with at least one day of not usual job performance/ not usual level of activity, ${ }^{\mathrm{k}}$ for those still in need of family/ friends caregiver help - time from CAP diagnosis till last survey

Note: Among currently employed- $p$-value is for difference between age $<50$ and age 50-64; among not currently employed- $p$-value is for difference between age $<50$, age $50-64$ and age $>65$

$\mathrm{CAP}=$ community-acquired pneumonia; $\mathrm{COPD}=$ chronic obstructive pulmonary disease; $\mathrm{SD}=$ standard deviation; $\mathrm{Q} 1-\mathrm{Q} 3=$ interquartile range 
Table 4. Comparisons of a COPD and Community Population of CommunityAcquired Pneumonia Sufferers---Selected Symptom Frequency and Time to Resolution ${ }^{19,20}$

\begin{tabular}{|c|c|c|c|c|}
\hline & $\begin{array}{c}\text { Our COPD } \\
\text { Population } \\
\quad \mathrm{N}=481\end{array}$ & $\begin{array}{l}\text { Time to } \\
\text { Resolution } \\
\text { Mean }\end{array}$ & $\begin{array}{c}\text { Wyrwich's } \\
\text { Community } \\
\text { Population } \\
\mathrm{N}=500\end{array}$ & $\begin{array}{c}\text { Time to } \\
\text { Resolution } \\
\text { Mean }\end{array}$ \\
\hline & $\%$ & Days & $\%$ & Days \\
\hline Have Self-reported COPD & 100 & NA & 24.4 & NA \\
\hline Hospitalized for CAP & 91.1 & NA & 40.3 & NA \\
\hline Cough $^{d}$ & 99.0 & 43.1 & 98.3 & 15.4 \\
\hline Thick Mucus or Phlegm with Cough ${ }^{b, f}$ & 92.7 & 37.8 & 75.5 & 15.3 \\
\hline Tiredness & 99.8 & 27.2 & 98.0 & 21.2 \\
\hline Dyspnea $^{d}$ & 95.8 & 35.5 & 89.1 & 22.8 \\
\hline Confusion/Trouble Thinking,f & 60.0 & 13.9 & 33.0 & 9.6 \\
\hline Wheezinga,f & 91.1 & 34.6 & 85.8 & 18.6 \\
\hline Trouble Sleeping, & 88.8 & 46.5 & 70.3 & 20.5 \\
\hline Required Help & 84.6 & 28.2 & 77.4 & 13.7 \\
\hline Missed Work (among those employed) & 96.9 & 21.4 & 92.5 & 9.8 \\
\hline Missed Usual Activities (among those not employed) & 87.5 & 36.4 & 74.1 & 14.7 \\
\hline
\end{tabular}

Figure 3. Percentage of Patients Reporting Adverse Impact of Community-Acquired Pneumonia Symptoms on Activities

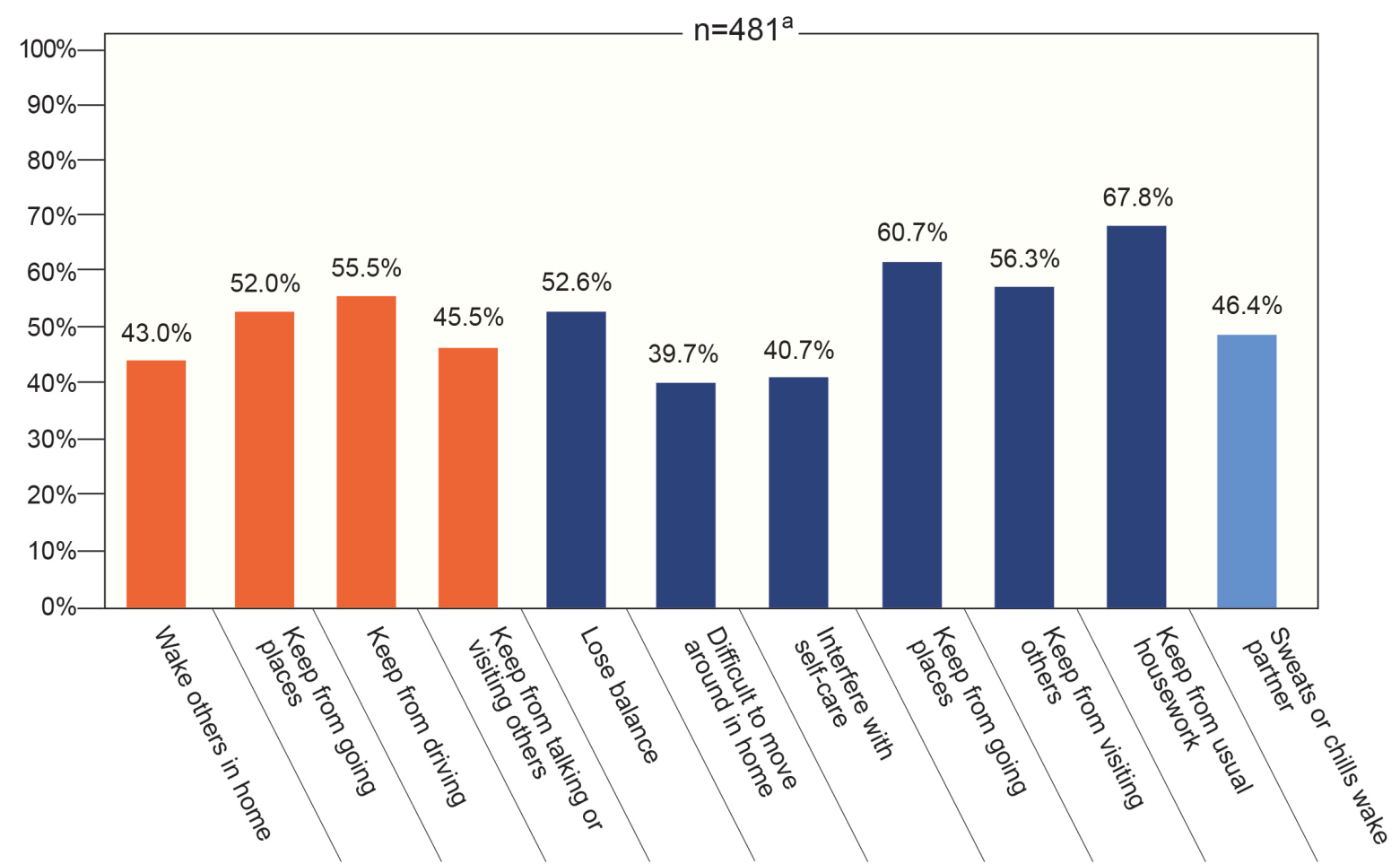

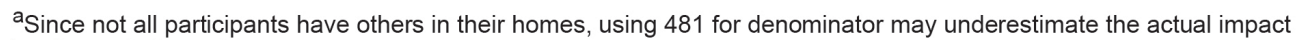

$\square$ Impact of coughing

Impact of weakness

$\square$ Other impact 
had COPD. Symptom frequency was lower for all symptoms except cough with less than $80 \%$ reporting dyspnea (shortness of breath), less than $70 \%$ reporting sputum production and less than $40 \%$ reporting fever compared to $95.8 \%, 93.8 \%$ and $88.8 \%$, respectively, in our study participants. Although the patients in the Canadian study were older on average, our group with COPD were more symptomatic, and compared to other groups of patients, also required longer to have symptoms resolve and allow for the return to work.

Other earlier studies of symptom burden in CAP provide additional context to our study results. ${ }^{27,28}$ Among "low risk" patients studied, e.g., those without major chronic comorbidities, median time to symptom "cure" was 21 days with fatigue and cough being the slowest to resolve. While the time to symptom recovery is longer among our participants, the long duration of cough and tiredness or fatigue are similar with $51 \%$ of the patients in that study reporting continued fatigue at 90 days post pneumonia diagnosis. ${ }^{27}$ In studies of patients hospitalized with bacteremic pneumococcal pneumonia, mean time to return to work was 16 days $^{29}$ while in the PORT study of patients treated in an ambulatory setting, pneumonia was associated with a much shorter time to return to work, with an average of 7 days. ${ }^{30}$

While we did not formally collect any qualitative data, an opportunity to offer comments was provided. Some of those comments illustrate powerful images of the impact of CAP on people already living with COPD. The image of a "prison" limiting all activity and interactions and the need to again downgrade the anticipated "norm" for activities are both disheartening and revealing.

Many cases of CAP are preventable with smoking cessation and completion of recommended pneumococcal vaccines and yearly influenza vaccination. ${ }^{31-36}$ Almost half of this study's participants reported themselves to be current smokers providing a significant prevention opportunity. In addition, the 2016 Behavioral Risk Factor Surveillance System (BRFSS) data reports $64.3 \%$ of individuals with COPD self-report having received a pneumococcal vaccine. ${ }^{37}$ The Centers for Disease Control and Prevention (CDC) reports that in the 2016-2017 influenza season, $43.3 \%$ of adults $\geq 18$ years of age received a flu vaccine. ${ }^{38}$ The most recent CDC survey data from 2016 indicates that $66.9 \%$ of adults $\geq 65$ years of age received a pneumococcal vaccine. $^{39}$ These data are well below the Healthy People 2020 goals of $70 \%$ and $90 \%$ for influenza and pneumococcal vaccination in these populations, respectively. ${ }^{40}$ These data highlight an opportunity for health care providers to improve influenza and pneumococcal immunization rates among their COPD patient population. In our study population, nearly half of this study population reported themselves to be current smokers, providing another prevention opportunity. Educational opportunities to underscore the importance of immunizations and smoking cessation among COPD patients and health care providers should be utilized.

This study has several strengths as well as limitations that may affect the generalizability of the results. It is a strength that we collected information directly from patients. Patients are the best source of information related to symptom prevalence, duration and impact on their daily lives, though reliance on self-report may be less reliable for reports of medical diagnoses. However, self-report of CAP and COPD may have introduced some error into these measurements, including the presence and timing of CAP and the validity of the COPD diagnoses. The timing of the self-report may also be a limitation as this study required individuals to recall CAP symptoms that on average occurred 70 days prior to their report on the baseline survey. This is particularly true for those individuals whose symptoms resolved fairly quickly, as the recall period for those who had longer-lasting symptoms would be shorter for the same time elapsed since diagnosis; presumably there would not be recall bias for those whose symptoms persisted to the time of the survey. Likewise, as the follow-up focused on symptoms still present at the time of the baseline survey, recall from the follow-up survey may be of less concern since it required only 30 days of recall. The study was conducted online, potentially limiting participants to those with higher technological literacy or only those who have access to the internet. In addition, the sampling frame from which participants were recruited may not fully represent COPD patients with CAP as a whole, as participants were recruited through the resources of a patient advocacy organization. Finally, it is possible that self-selection resulted in a sample with more severe COPD who have higher risk of exacerbations and CAP. However, this is an important population since many health care professionals and policy makers may forget that the population with COPD and CAP 
includes many individuals who experience not only disruption to their usual activities but also extended absence from jobs.

\section{Conclusions and Practice and Patient-Related Implications}

In individuals with COPD, CAP results in a significant and lengthy burden affecting families and caregivers as well as the patient. Efforts to improve the provision of CAP prevention strategies including supporting smoking cessation and increasing pneumococcal and annual influenza immunizations are needed.

\section{Acknowledgements}

The authors thank David Mannino, MD, for his substantial work on and contributions to the CAP Study. The authors also wish to sincerely thank the late Edna Shattuck for her contributions to the study team and for her tireless work for the COPD community.

The research reported in this publication was conducted using PCORnet ${ }^{\circledR}$, the National PatientCentered Clinical Research Network, an initiative funded by the PCORI. The statements presented in this publication are solely the responsibility of the author(s) and do not necessarily represent the views of organizations participating in or collaborating with PCORnet ${ }^{\circledR}$ or of PCORI.

Author Contributions: Ms. Pasquale made substantial contributions to the conception and design of the study, oversaw data acquisition and writing the article and revised the paper in response to co-author comments. Dr. Vietri contributed to the design of the study, data interpretation, and reviewing the article. Ms. Choate designed and conducted data analysis, significantly contributed to data interpretation, and writing and reviewing the article. Dr. McDaniel contributed to conception and design of the study and revising the article. Dr. Sato contributed to the conception and design of the study, data interpretation, and reviewing the article. Dr. Ford contributed to the conception and design of the study, data interpretation, and reviewing the article. Ms. Malanga made substantial contributions to the conception and design of the study, data acquisition, and writing and reviewing the paper. Dr. Yawn oversaw data analysis and made substantial contributions to data interpretation, writing the article and revising the paper in response to coauthor comments. Dr. Yawn developed the original draft of the manuscript and all authors reviewed and revised it for important intellectual content.

\section{Declaration of Interest}

J. Vietri, A. McDaniel, R. Sato and K.D. Ford are employees and stock holders of Pfizer, Inc. B.P. Yawn reports serving on advisory boards for GlaxoSmithKline, AstraZeneca and Boehringer Ingelheim related to COPD. All other authors have nothing to declare. 


\section{References}

1. Brar NK, Niederman MS. Management of community-acquired pneumonia: A review and update. Ther Adv Respir Dis. 2011;5(1):61-78. doi: https://doi.org/10.1177/1753465810381518

2. File TM Jr, Marrie TJ. Burden of community-acquired pneumonia in North American adults. Postgrad Med. 2010;122(2):130-141. doi: https://doi.org/10.3810/pgm.2010.03.2130

3. Jackson ML, Neuzil KM, Thompson WW, et al. The burden of community acquired pneumonia in seniors: results of a population-based study. Clin Infect Dis. 2004;39(11):1642-1650. doi: https://doi.org/10.1086/425615

4. Mullerova H, Chigbo C, Hagan GW, et al. The natural history of community-acquired pneumonia in COPD patients: a population database analysis. Respir Med. 2012;106(8):11241133. doi: https://doi.org/10.1016/j.rmed.2012.04.008

5. Mangen M-J, Huijts SM, Bonten MJM, de Wit GA. The impact of community-acquired pneumonia on the health-related quality of-life in elderly. BMC Infect Dis. 2017;17:208.

doi: https://doi.org/10.1186/s12879-017-2302-3

6. Healthcare Cost and Utilization Project (HCUP). Data use agreement for HCUPnet. Agency for Healthcare Research Quality website.

https://hcupnet.ahrq.gov/\#query/ eyJBTkFMWVNJU19UWVB FIjpbIkFUX00iXSwiQ0FURUdPUklaQVRJT05fVFlQRSI6WyJ DVF9DQ1NEIlOsIkRBVEFT RVRfU09VUkNFIjpbIkRTX05JUy JdLCJZRUFSUyI6WyJZUl8y MDEOIlosIlBS SU 5DSVBM RV9PUl9BTEwiOlsiUEFfUFJJTkNJUExFI losIlBBVElFTlRfQ0 hBUiI6WyJQQ19QQUNNIlosIk9VVENPTUVfTUVBU1VSR VMiOlsiT01fTlVNQkVSIiwiT01fSEN IIiwiT01fSENPIiwiT01fQ UNIIiwiT01fQUNPIiwiT01fRElFRF 9HUlAiXSwiQ1RfQ0NTR CI6WyI0OTAxIl19 Accessed March 2018.

7. Mirza S, Benzo R. Chronic obstructive pulmonary disease phenotypes: implications for care. Mayo Clin Proc. 2017; 92(7):1104-1112

doi: http://dx.doi.org/10.1016/j.mayocp.2017.03.020

8. Thornton Snider J, Romley JA, Wong KS, Zhang J, Eber M, Goldman DP. The disability burden of COPD. COPD. 2012; 9(5):513-521.

doi: https://doi.org/10.3109/15412555.2012.696159

9. Lin SH, Perng DW, Chen CP, et al. Increased risk of communityacquired pneumonia in COPD patients with comorbid cardiovascular disease. Int $J$ Chron Obstruct Pulmon Dis. 2016;11(1):3051-3058.

doi: https://doi.org/10.2147/COPD.S115137

10. Shukla SD, Hansbro PM, Walters EH. Upregulated pneumococcal adhesion molecule (platelet-activating factor receptor) may predispose COPD patients to community-acquired pneumonia. Int J Chron Obstruct Pulmon Dis. 2017;12:3111-3113. doi: https://doi.org/10.2147/COPD.S151142
11. Torres A, Blasi F, Dartois N, Akova M. Which individuals are at increased risk of pneumococcal disease and why? Impact of COPD, asthma, smoking, diabetes, and/or chronic heart disease on community-acquired pneumonia and invasive pneumococcal disease. Thorax. 2015;70(10):984-989. doi: https://doi.org/10.1136/thoraxjnl-2015-206780

12. Rello J, Rodriguez A, Torres A, et al. Implications of COPD in patients admitted to the intensive care unit by communityacquired pneumonia. Eur Respir J. 2006; 27(6):1210-1216. doi: https://doi.org/10.1183/09031936.06.00139305

13. Ryan M, Suaya JA, Chapman JD, Stason WB, Shepard DS, Thomas CP. Incidence and cost of pneumonia in older adults with COPD in the United States. PloS One. 2013;8(10):e75887. doi: https://doi.org/10.1371/journal.pone.0075887

14. Snijders D, van der Eerden M, de Graaff C, Boersma W. The influence of COPD on mortality and severity scoring in community-acquired pneumonia. Respiration. 2010;79(1):46-53. doi: https://doi.org/10.1159/000213757

15. Bornheimer, R, Shea KM, Sato R, Weycker D, Pelton SI. Risk of exacerbation following pneumonia in adults with heart failure or chronic obstructive pulmonary disease. PLoS One. 2017;12(10):e0184877.

doi: https://doi.org/10.1371/journal.pone.0184877

16. Anzueto A. Impact of exacerbations on COPD. Eur Respir Rev. 2010;19(116):113-118.

doi: https://doi.org/10.1183/09059180.00002610

17. Wedzicha JA, Wilkinson T. Impact of chronic obstructive pulmonary disease exacerbations on patients and payers. Proc Am Thorac Soc. 2006;3(3):218-221.

doi: https://doi.org/10.1513/pats200510-114SF

18. Takir HB, Esquinas AM. Community-acquired pneumonia and survival of critically ill acute exacerbation of COPD patients in respiratory intensive care units. Int J Chron Obstruct Pulmon Dis. 2017;12:783-784. doi: https://doi.org/10.2147/COPD.S 124812

19. Wyrwich KW, Yu H, Sato R, Strutton D, Powers JH. Communityacquired pneumonia: symptoms and burden of illness at diagnosis among US adults aged 50 years and older. Patient. 2013;6(2);125-134.

doi: https://doi.org/10.1007/s40271-013-0013-4

20. Wyrwich KW, Yu H, Sato R, Strutton D, Powers JH. Observational longitudinal study of symptom burden and time for recovery from community-acquired pneumonia reported by older adults surveyed nationwide using the CAP Burden of Illness Questionnaire. Patient Related Outcome Measures. 2015;6:215223. doi: http://dx.doi.org/10.2147/PROM.S85779

21. Marrie TJ, Lau CY, Wheeler SL, Wong CJ, Feagan BG. Predictors of symptom resolution in patients with community-acquired pneumonia. CID. 2000;231:1362-1367. 
22. Marrie TJ, Beecroft MD, Herman-Gnjidic Z. Resolution of symptoms in patients with community -acquired pneumonia treated on an ambulatory basis. J Infection. 2004;49:302-309.

23. Torres A, Ewig S. The strange case of community-acquired pneumonia in COPD. Chest. 2011;139(3):483-485. doi: https://doi.org/10.1378/chest.10-2227

24. de Miguel-Diez J, Lopez-de-Andes A, Hernandez-Barrera V, et al. Impact of COPD on outcomes in hospitalized patients with community- acquired pneumonia: analysis of the Spanish national hospital discharge database (2004-2013). Eur J Intern Med. 2017;43:69-76.

doi: https://doi.org/10.1016/j.ejim.2017.06.008

25. Williams NP, Coombs NA, Johnson MJ, et al. Seasonality, risk factors and burden of community-acquired pneumonia in COPD patients: A population database study using linked health care records. Int J Chron Obstruct Pulmon Dis. 2017;12:313-322. doi: https://doi.org/10.2147/COPD.S121389

26. JonesPW,Harding G,BerryP,etal.Developmentandfirstvalidation of the COPD Assessment Test. Eur Respir J. 2009;34(3):648-654. doi: https://doi.org/10.1183/09031936.00102509

27. Metlay JP, Fine MF, Schulz R, et al. Measuring symptomatic and functional recover in patients with community acquired pneumonia. J Gen Intern Med. 1997;12(7):423-430. doi: https://doi.org/10.1046/j.1525-1497.1997.00074.x

28. Metlay JP, Atlas SJ, Borowshy LH, Singer DE. Time course of symptom resolution in patients with community-acquired pneumonia. Respir Med. 1998;92:1137-1142. doi: https://doi.org/10.1016/S0954-6111(98)90408-5

29. Brandenburg JA, Marrie TJ, Coley CM, et al. Clinical presentation, processes and outcomes of care for patients with pneumococcal pneumonia. J Gen Intern Med. 2000;15:638-646. doi: https://doi.org/ 10.1046/j.1525-1497.2000.04429.x

30. Fine MJ, Stone RA, Singer DE, et al. Processes and outcomes of care for patients with community-acquired pneumonia. Results from the pneumonia patient outcomes research team (PORT) cohort study. Arch Intern Med. 1999;159(9):970-980.

doi: https://doi.org/10.1001/archinte.159.9.970

31. Bekkat-Berkani R, Wilkinson T, Buchy P, et al. Seasonal influenza vaccination in patients with COPD: A systematic literature review. BMC Pulm Med. 2017;17(1):79.

doi: https://doi.org/10.1186/s12890-017-0420-8.

32. Stanbrook MB. Review: In COPD, injectable polyvalent pneumococcal vaccines reduce risk for community-acquired pneumonia. Ann Intern Med. 2017;166(10):JC52. doi: https://doi.org/10.7326/ACPJC-2017-166-10-052.

33. Eagan TM, Hardie JA, Jul-Larsen Ã, Grydeland TB, Bakke PS, Cox RJ. Self-reported influenza vaccination and protective serum antibody titers in a cohort of COPD patients. Respir Med. 2016; 115:53-59. doi: https://doi.org/10.1016/j.rmed.2016.04.008
34. Kositanont U, Wongsurakiat P, Pooruk P, Maranetra N, Puthavathana P. Induction of cross-neutralizing antibody against $\mathrm{H} 5 \mathrm{~N} 1$ virus after vaccination with seasonal influenza vaccine in COPD patients. Viral Immunol. 2010;23(3):329-334. doi: https://doi.org/10.1089/vim.2009.0082

35. Sehatzadeh S. Influenza and pneumococcal vaccinations for patients with chronic obstructive pulmonary disease (COPD): an evidence-based analysis. Ont Health Technol Assess Ser. 2012;12(3):1-64. www.hqontario.ca/en/mas/tech/pdfs/2012/rev _COPD_Vaccinations_March.pdf.

Published March 2012. Accessed March 2018.

36. Mandell LA1, Wunderink RG, Anzueto A, et al; Infectious Diseases Society of America; American Thoracic Society. Infectious Diseases Society of America/American Thoracic Society consensus guidelines on the management of communityacquired pneumonia in adults. Clin Infect Dis. 2007;44 (Suppl 2):S27-72. doi: https://doi.org/10.1086/511159

37. Centers for Disease Control and Prevention (CDC). Behavioral Risk Factor Surveillance System. CDC web site. http://www.cdc. gov/brfss/about/. Published May 16, 2014. Accessed December 13, 2017.

38. Centers for Disease Control and Prevention (CDC). Influenza (Flu): flu vaccination coverage, United States, 2016-17 influenza season. CDC website. https://www.cdc.gov/flu/fluvaxview/cove rage-1617estimates.htm

Updated September 28, 2017. Accessed March 2018.

39. Centers for Disease Control and Prevention (CDC). Health insurance coverage: early release of estimates from the National Health Interview Survey, 2016. CDC website. https://www.cdc. gov/nchs/data/nhis/earlyrelease/Earlyrelease201705_05.pdf Published May 2017. Accessed March 2018.

40. Office of Disease Prevention and Health Promotion (ODPHP) Heathy People 2020 - Immunization and infectious diseases. ODPHP website. https://www.healthypeople.gov/2020/topicsobjectives/topic/immunization-and-infectious-diseases/ objectives

Accessed March 2018. 